\title{
O consumo cultural de jovens no Brasil profundo: uma experiência qualitativa na Microrregião de Propriá (SE) ${ }^{1}$
}

\author{
Cultural consumption of young people in deep Brazil: a \\ qualitative experience in the Propriá (SE) Microregion.
}

\section{El consumo cultural de los jóvenes en el Brasil profundo: una experiencia cualitativa en la Microrregión de Propriá (SE)}

\author{
Maria Beatriz Filgueiras \\ Graduanda em Comunicação Social com Habilitação em Publicidade e \\ Propaganda da Universidade Federal de Sergipe. \\ Universidade Federal de Sergipe. \\ http://lattes.cnpq.br/7533042616928677 \\ beafilgueiras@gmail.com
}

Suelem Lopes de Freitas

Mestranda no Programa de Pós-Graduação em Comunicação e Informação da

$$
\text { FABICO-UFRGS }
$$

Universidade Federal do Rio Grande do Sul

http://lattes.cnpq.br/5116541430037952

s.freitas555@gmail.com

Malu de Araújo Freitas

Estudante de Jornalismo da Universidade Federal de Sergipe

Universidade Federal de Sergipe

http://lattes.cnpq.br/6759395708123719

malu.ojuara.1@gmail.com

Matheus Pereira Mattos Felizola

Publicitário e Administrador de Empresas. Doutor em Ciências Sociais e

Professor do PPGCOM/ PPGCI da Universidade Federal de Sergipe

https://orcid.org/0000-0002-7826-4511

http://lattes.cnpq.br/5611829504195938

contato@matheusfelizola.com.br 


\section{Vitor José Braga Mota Gomes}

Jornalista, mestre e doutor em Comunicação e Cultura Contemporâneas.

Professor do Departamento de Comunicação Social (DCOS) e do Programa de Pós-Graduação em Comunicação (PPGCOM) da Universidade Federal de

\section{Sergipe}

https://orcid.org/0000-0002-2377-9323

http://lattes.cnpq.br/5116911792600055

vitorbragamg@gmail.com

Resumo: O presente artigo teve como objetivo analisar o uso do WhatsApp enquanto uma ferramenta de conversação nas mídias sociais para os jovens do Nordeste, especificamente do interior de Sergipe. A pesquisa foi realizada entre os anos de 2017 e 2019 na microrregião geográfica de Propriá, no Estado de Sergipe, e os dados que serão apresentados neste trabalho científico são oriundos da análise de conteúdo realizada a partir do método proposto por Bardin (2016) de entrevistas semi-estruturadas realizadas com 100 jovens entre 18 e 24 anos de dez cidades da região. Como reflexão teórica, o texto perpassa por Lemos, Lévy, Thompson e Recuero e pelo estado da arte de pesquisas similares com jovens imersos no processo de convergência midiática. Como resultados, percebe-se que, no contexto das entrevistas realizadas, o aplicativo de mensagens instantâneas WhatsApp é a ferramenta de comunicação mais utilizada pelos jovens entrevistados, tanto para manter relacionamentos com seus pares como para buscar informações.

Palavras-chave: Juventude. Consumo cultural. convergência midiática.

Abstract: The present article aims to analyze the use of WhatsApp as a communication tool for young people in the Northeast, specifically those in the interior of Sergipe. The research was carried out between 2017 and 2019 in the Propriá geographic microregion in the State of Sergipe and the data that will be presented in this scientific work come from the analysis of content made from the method proposed by Bardin (2016) of semi- structured interviews with 100 young people from age 18 to 24 out of ten cities in the region. As for a theoretical reflection, the paper perpass through Lemos, Lévy, Thompson and Recuero and for the state of the art of similar research with young people immersed in the process of media convergence. As a result it is possible to notice that, in the context of the interviews, the instant messaging application WhatsApp is the communication tool most used by young interviewee in the micro-region, both to maintain relationships with peers and to seek relevant information.

Keywords: Youth. Cultural consumption. media convergence. 
Resumen: Este artículo tiene como objetivo analizar el uso de WhatsApp como herramienta de comunicación para los jóvenes del noreste, específicamente del interior de Sergipe. La investigación se realizó entre 2017 y 2019 en la microrregión geográfica de Propriá en el estado de Sergipe y los datos que se presentarán en este trabajo científico provienen del análisis de contenido realizado utilizando el método propuesto por Bardin (2016) de semi-entrevistas. estructurado con 100 jóvenes de entre 18 y 24 años de diez ciudades de la región. Como una reflexión teórica, el texto pasa por Lemos, Lévy, Thompson y Recuero y el estado del arte de una investigación similar con jóvenes inmersos en el proceso de convergencia de medios. Como resultado, está claro que la aplicación de mensajería instantánea de WhatsApp es la herramienta de comunicación más utilizada por los jóvenes entrevistados, tanto para mantener relaciones con sus pares como para buscar información.

Palabras clave: Juventud. Consumo cultural. Convergencia de medios.

\section{Introdução}

A conversação, enquanto instrumento da comunicação em co-presença, sempre esteve ligada à mediação do contexto, que por sua vez é formatado sob vários aspectos socioeconômicos e culturais (THOMPSON, 2012). Nas regiões do interior do Nordeste brasileiro, tais aspectos costumam apresentar muitas diferenças se comparados às regiões metropolitanas dos estados que o compõem, resultando em uma desigualdade social entre estas localidades (Silva, 2019). Isto nos leva a compreender que estamos, na verdade, falando de juventudes: são múltiplas vozes em um país com dimensões continentais, em que essa desigualdade vem a ocasionar diferentes condições de acesso aos mais diversos produtos e serviços.

A primeira visão de conversação promovida por tecnologias digitais aconteceu a partir do conhecimento da interação por diálogos formados textualmente, permitidos pelas páginas de webchat e correios eletrônicos (RHEINGOLD, 2007). Devemos levar em consideração que a conversação no ciberespaço está diretamente relacionada com as inovações tecnológicas que a envolvem, de modo que, com os avanços dos dispositivos comunicacionais móveis, estes passaram a se configurar como um espaço conversacional, conseguindo influenciar e até modificar os métodos conversacionais comuns no ciberespaço (RECUERO, 2014). 
Conforme Recuero (2014), a conversação é aquilo que conduz as interações sociais, pois é através dela que as relações interpessoais são submetidas e os laços construídos. Nessas ambiências digitais, os interlocutores não visualizam uns aos outros face a face, e por isso não é possível identificar deixas gestuais e auditivas. Embora isto atrapalhe o processo interativo, pois limita a compreensão dos diálogos desenvolvidos pelos interlocutores, temos por outro lado um desenvolvimento de múltiplos cenários para a conversação, onde os jovens podem se relacionar com vários usuários desses aplicativos e estar em contato com outras pessoas em co-presença simultaneamente.

Os dispositivos comunicacionais móveis são assim capazes de promover a experiência da mediação em mobilidade, como é o caso dos smartphones, que ampliaram a conversação textual antes apenas restrita ao $S M S^{2}$ e $M M S^{3}$. Temos assim a eclosão de aplicativos de mensagens instantâneas como o Whats App ${ }^{4}$, capaz de agregar pessoas através do número de telefone dos aparelhos, bem como promover fóruns de discussão por intermédio dos grupos nele criados.

No presente artigo, enfocamos o uso do WhatsApp enquanto ferramenta de comunicação com os jovens do Nordeste, especificamente daqueles do interior de Sergipe, na microrregião de Propriá. Entendemos que, ao voltarmos nosso olhar para essa realidade, podemos trazer subsídios para a compreensão dos usos e apropriações dessa parcela da população brasileira em contextos pouco explorados em âmbito acadêmico, tendo em vista que a maioria dos artigos e ensaios tendem a observar aqueles que habitam regiões metropolitanas.

Em relação aos procedimentos metodológicos, realizamos uma pesquisa exploratória cujo instrumento escolhido foram as entrevistas semi-estruturadas com jovens de 18 a 24 anos que habitavam alguma das dez cidades componentes da Microrregião de Propriá ${ }^{5}$. Para lidar com esses dados coletados, realizamos uma análise de conteúdo, conforme preceitua Bardin (2016).

Cabe-nos refletir como diferentes contextos socioculturais e midiáticos são capazes de promover diferentes usos e apropriações da conversação mediada pelas tecnologias digitais, e como podemos identificar traços de culturas regionais em ambiências digitais com tendências globalizantes. Sendo assim, 
pretendemos compreender o consumo midiático em um cenário caracterizado pela convergência midiática (Jenkins, 2009; Jenkins \& Green, 2014).

Partimos do pressuposto de que os dispositivos tecnológicos e as mídias sociais, inseridos nas vivências desses jovens pesquisados, proporcionam significativas modificações nas relações que estes desenvolvem com a mídia, estimulando novas sociabilidades e diferentes maneiras de inserção social (Jacks et al, 2017). De acordo com Martín-Barbero (2014), as TICs se tornam mediadoras das relações dos jovens no contexto da América Latina, contribuindo para a manutenção de laços, vínculos, crenças e costumes, colaborando para a sustentabilidade cultural no contexto de vivência.

\section{Ciberespaço e as Participações do Jovem na Rede}

Por meio da perspectiva de Lemos (2005) é possível compreender que, com a ascensão da web, surgiu a possibilidade de estar conectado a todo instante, em todos os lugares e em tempo real. Nesse contexto encontra-se a cibercultura, termo proposto por Lévy (1999) para referir-se a tudo que ocorre tendo como palco o ciberespaço: a rede mundial de computadores. Segundo Lévy (1999), a cibercultura é, então, um produto do ciberespaço, que permite uma comunicação a partir da interconexão de computadores via World Wide Web.

Estes novos modos de comunicação são responsáveis por diversas mudanças, inclusive no âmbito sociocultural. A partir de Lemos (2009), observa-se que o surgimento de novas tecnologias de comunicação e informação posiciona tais tecnologias como vetores de agregação social, criando vínculos comunicacionais e proporcionando a recombinação de informações em formatos variados, sejam estes textos, imagens fixas, imagens animadas ou sons. Assim, a cultura pós-massiva permite observar o movimento de recombinação cultural dentro de um ambiente eletrônico presente em todo o mundo.

Tal como pontuado por Santaella (2004), a interação entre o mundo virtual e "real" relaciona-se às constantes mudanças na sociedade, decorrentes da cibercultura. Assim, os indivíduos se encontram em um estado de ubiquidade, 
dividindo sua atenção entre os acontecimentos do mundo digital e o que acontece fora dele, de modo a permitir uma mesclagem de interatividade nesses espaços.

Nesse estado de ubiquidade é importante mencionar a comunicação em mobilidade, proporcionada pelos dispositivos comunicacionais móveis, especialmente os smartphones, com ampla aceitação pelo público jovem. Estes aparelhos proporcionam experiências de interação entre espaços conversacionais decorrentes da interação em co-presença, ao mesmo tempo em que proporcionam uma ambiência digital para desenvolver uma conversação (RECUERO, 2014).

Em nossa pesquisa, é importante considerar os jovens como um público importante desses dispositivos pela capacidade que estes possuem de gerenciar esses espaços conversacionais - entre os ambientes de co-presença e as ambiências digitais, como o WhatsApp. Essa capacidade dos jovens, conforme Martín-Barbero (2014), é reflexo do desenvolvimento das TICs, que ampliam o horizonte de reciprocidade de cada indivíduo com os outros no mundo e, assim, amplificam os espaços de possibilidade de existência e fortalecimento de sujeitos.

Compreende-se, ainda, sob a perspectiva de Granero e Couto (2013), a juventude pertencente às gerações $\mathrm{Y}$ e $\mathrm{Z}$ como principais usuárias da Web, considerando as mídias sociais enquanto importantes ferramentas no cotidiano desses jovens. Nesta perspectiva, é possível destacar o consumo de aplicativos a fim de resolver os mais diversos problemas da vida cotidiana - como, por exemplo, criar listas de supermercado, conferir a agenda de compromissos da semana, criar e compartilhar conteúdo com amigos e até escolher alguém com quem se relacionar.

Ademais, de acordo com Oliveira e Barbalho (2017, p. 87), faz-se necessário compreender que o acúmulo de "capital tecnológico", em um contexto de compartilhamento de informações e conectividade prolongada, mostra-se como uma maneira de distinção entre indivíduos, inclusive no campo social. Deste modo, no caso dos jovens, tal capital firma-se como palco e como tela de suas relações.

Inserido nesse panorama, a aplicação de mensagens instantâneas WhatsApp tem, desde o seu surgimento, se mostrado como uma das principais 
aplicações utilizadas pelos jovens para se comunicar (TIC, 2016), de modo que torna-se importante compreender seus usos e apropriações por parte destes.

\subsection{O Fenômeno do WhatsApp Enquanto Mídia Social}

Criado no ano de 2009 e pertencente ao grupo Facebook desde 2014, o aplicativo gratuito de troca de mensagens WhatsApp Messenger é uma mídia social que de destaque no que diz respeito à comunicação via internet. Segundo definição disponível no próprio site oficial da plataforma ${ }^{6}$, "O WhatsApp surgiu como uma alternativa ao sistema de SMS e agora possibilita o envio e recebimento de diversos arquivos de mídia: fotos, vídeos, documentos e localização, além de textos e chamadas de voz". Compreende-se a ferramenta como uma mídia social, visto que, por mídias sociais, concerne-se a perspectiva de que estas são espaços de interação entre usuários, onde se pode dialogar e compartilhar informação, e cujo conteúdo tende ao infinito, pois qualquer membro pode contribuir a qualquer momento, construindo blocos colaborativos de opinião e trocas de informação (SOUZA; ARAUJO; PAULA, 2015).

No aplicativo em questão, entendemos como uma importante ferramenta para a conversação nas mídias sociais. Isto porque seu uso ocorre em larga escala no contexto global: em 2016, por exemplo, o aplicativo atingiu a marca de um bilhão de usuários no mundo (WhatsApp, 2016). Além disso, em 2018, ele foi o aplicativo de troca de mensagens líder de utilização em 112 de mais de 180 países pesquisados (SIMILAR WEB, 2018). No Brasil, essa realidade não é diferente: em 2017, a empresa divulgou para a imprensa que o número de usuários do aplicativo no país chegou a 120 milhões (WhatsApp, 2017). Já o IBGE (2017) destacou que 95,5\% dos brasileiros utiliza a Internet com a finalidade de enviar ou receber mensagens de texto, voz ou imagens por aplicativos (sem considerar o uso de e-mail). É possível assim perceber a expressividade dessa forma de comunicação no Brasil.

No que diz respeito às suas funcionalidades, destacamos que os jovens da nossa pesquisa costumam fazer dois usos majoritários: o primeiro é o envio de mensagens individuais diretas, funcionalidade que, apesar das características 
próprias relativas ao ciberespaço, é a que mais se assemelha às relações interpessoais no que tange à emissão e recepção da mensagem, pois se trata de um emissor único entregando a sua mensagem para um receptor único. Já o segundo uso refere-se às mensagens em grupo: em nossa pesquisa pudemos observar que esta agrega pessoas acerca de um propósito em comum, como colegas de escola, faculdade ou trabalho; familiares; grupos de amigos da localidade ou egressos da escola; e grupos de interesse voltados a discutir um tema específico. Para a criação desses espaços de conversa, há a figura de um administrador que convida as pessoas. Nessa dinâmica, cabe destacar que, desde abril de 2019, existe a necessidade prévia de aceitação da pessoa convidada para ingressar no grupo. No entanto, durante o período de realização desta pesquisa, essa necessidade não era uma realidade para os jovens de nosso corpus.

A partir dessas características, podemos reforçar o princípio da liberação do polo de emissão proposto por Lemos (2009), visto que, com o uso do WhatsApp, cada usuário é, em potencial, um produtor de conteúdo (e também um receptor) a partir de uma dinâmica livre e multimodal de emissão de informações. Já Souza, Araújo e Paula (2015, p. 140) acrescentam ao debate as possibilidades de interação e discussão que o WhatsApp proporciona, ao trazerem como ponto de destaque o fato de que, neste tipo de canal, é possível dialogar e compartilhar as mais diversas informações; deste modo, é possível compreender que o conteúdo presente em uma mídia social tende ao infinito, já que, a qualquer momento, qualquer membro pode contribuir para a construção desse conteúdo. Nessa perspectiva, torna-se relevante discutir e analisar as apropriações desse recurso de comunicação pelos jovens, trazendo à tona os usos que estes lhe dão e as particularidades do contexto o qual fazem parte.

\section{Procedimentos Metodológicos}

A presente pesquisa resulta de uma reflexão sobre os resultados obtidos pelo Grupo de Pesquisa de Marketing (GPM) da UFS, a partir de pesquisas empíricas realizadas na microrregião de Propriá, constituída por dez municípios, no estado de Sergipe, como parte do projeto "Jovens e Consumo Midiático em Tempos de Convergência"7, com representação de três regiões brasileiras: Sul - 
sob a coordenação de Nilda Jacks, na Universidade Federal do Rio Grande do Sul (UFRGS) - e Norte - com a participação da Universidade Federal do Pará (UFPA). O projeto tem como principal intuito observar e comparar o consumo midiático entre jovens de 18 a 24 anos residentes das regiões anteriormente citadas, com o objetivo de compreender de que modo ocorre o consumo de mídias nas regiões afastadas das capitais - regiões estas as quais se deu o subtítulo "Brasil Profundo", seguindo uma inspiração na obra de Guillermo Bonfil Batalla, "México Profundo" (1990).

A fim de alcançar o objetivo de observar os usos e apropriações da ferramenta de comunicação WhatsApp pelos jovens da Microrregião de Propriá (SE), desenvolveu-se um trabalho exploratório com inspiração etnográfica. De acordo com Restrepo (2016), a etnografia interessa-se não apenas pelas práticas, como também pelos significados e sentidos por trás de tais práticas para os grupos investigados. A escolha pela Microrregião deu-se por meio de um conceito de divisão regional que vigorou no país até 2017, tendo como critério para escolha da Microrregião o fato de estar distante da zona de influência da Região Metropolitana de Aracaju.

Foram adotados diversos artefatos metodológicos a fim de obter contato com os jovens da Microrregião, sendo estes residentes em centros urbanos, comunidades rurais, comunidades ribeirinhas e comunidades quilombolas. Entre as técnicas utilizadas na pesquisa, é possível destacar a utilização de diários de campo, ações de observação direta, observações participantes, entrevistas semiestruturadas, além de registros audiovisuais e fotográficos e reuniões diárias entre as equipes.

Dentre os procedimentos de análise adotados após a pesquisa de campo, para as entrevistas realizadas com os jovens optamos pela análise de conteúdo, tal como proposta por Bardin (2016, p. 42). Conforme a autora, esta se refere a:

Um conjunto de técnicas de análises da comunicação visando obter, por procedimentos sistemáticos e objetivos de descrição do conteúdo das mensagens, indicadores (quantitativos ou não) que permitam a inferência de conhecimentos relativos às condições de produção/recepção (variáveis inferidas) destas mensagens. 
Conforme preceitua o método, realiza-se a criação de categorias e códigos de análise, a fim de compreender o número de ocorrências de cada código, as relações e cruzamentos entre códigos e categorias. A operação consistiu assim em trazer inferências a partir desses padrões de respostas encontrados nos discursos dos jovens. Interessa-nos também as conotações dos discursos, que muitas vezes têm mais a ver com as entrelinhas, as reticências, o subentendido e o tom do que é explícito.

Segundo Costa e Amado (2018), a produção de inferências assenta no estabelecimento de relações, com base em deduções lógicas e pertinentes, entre quatro polos diferenciados, que em nosso caso exploramos da seguinte forma: (1) os dados - no caso, as entrevistas realizadas; (2) os quadros de referências de quem produziu a comunicação - intenções, representações sociais, pressupostos etc.; (3) as condições de produção ou contexto de emergência desses mesmos dados de análise - o contexto socioeconômico e as condições de acesso dos jovens; e (4) os quadros de referência de quem analisa - exigindo que o analista esteja preparado teórica e metodologicamente para fazer as interpretações. Trata-se, em nosso caso, de uma análise voltada para a distinção de temas, o recorte de categorias e subcategorias no interior desses temas, e sobre a observação da sua frequência relativa no conjunto do corpus. Para tanto, utilizou-se o software NVivo (versão 12) a fim de auxiliar o trabalho de análise das 103 entrevistas realizadas.

Nesse artigo, trazemos então considerações de um dos aspectos trazidos nas entrevistas com os jovens: o uso das mídias sociais, especificamente para conversação. Deste modo, busca-se compreender os usos e apropriações do aplicativo WhatsApp pelos jovens de 18 a 24 anos no contexto social e econômico da Microrregião de Propriá, onde situa-se distante da região metropolitana e com condições de acesso às TICs com suas particularidades.

\section{Análise dos Dados}

Apresentamos, a seguir, os resultados referentes às entrevistas realizadas com os jovens, na faixa etária entre 18 e 24 anos, habitantes da Microrregião de Propriá. Para esta análise procuramos observar, sobretudo, os usos e 
apropriações nos relatos que contemplaram a conversação mediada pelo aplicativo WhatsApp nos dispositivos comunicacionais móveis. Selecionamos, então, o trabalho de análise realizado com base nos discursos dos entrevistados acerca de suas práticas de conversação nas mídias sociais conforme o Quadro 1:

Quadro 1: Códigos e subcódigos criados na análise de conteúdo realizada com o auxílio do NVivo.

\begin{tabular}{|c|c|}
\hline Códigos & Subcódigo \\
\hline Mídias Sociais Utilizadas & WhatsApp \\
\hline $\begin{array}{c}\text { Formas de contato com a } \\
\text { família }\end{array}$ & $\begin{array}{c}\text { WhatsApp } \\
\text { Grupos de WhatsApp }\end{array}$ \\
\hline $\begin{array}{c}\text { Formas de contato com } \\
\text { colegas de trabalho ou estudo }\end{array}$ & $\begin{array}{c}\text { WhatsApp } \\
\text { Grupos de WhatsApp }\end{array}$ \\
\hline Formas de contato com os & $\begin{array}{c}\text { WhatsApp } \\
\text { Grupos de WhatsApp }\end{array}$ \\
\hline Usos de grupos de & $\begin{array}{c}\text { Contato com colegas do colégio ou faculdade } \\
\text { Contato com amigos } \\
\text { Contato com a família } \\
\text { Apoio nos estudos }\end{array}$ \\
Acompanhar notícias \\
Acompanhar avisos da igreja
\end{tabular}

Fonte: pesquisa de campo. 
Dentre as mídias sociais mais utilizadas pelos jovens, o WhatsApp apareceu em primeiro lugar para 90 respondentes. Mas o Facebook praticamente empatou, com 89 dos entrevistados afirmando que o utilizam no seu dia-a-dia. Apresentamos abaixo algumas respostas a respeito dessa questão:

WhatsApp. WhatsApp é o melhor de todos né. Não tem condições. Tem que mexer no WhatsApp pois se não mexer, meu filho, aí dá depressão (risos). (Entrevistado 1, Nossa Senhora de Lourdes)

Mais, eu uso mais o WhatsApp que é melhor de se comunicar, mais rápido. (Entrevistado 1, Propriá)

Eu gosto muito de usar Facebook, mas geralmente eu uso mais o WhatsApp. (Entrevistado 1, Telha)

Como pode ser percebido, vários jovens citaram o referido aplicativo como o mais adequado dentre as mídias sociais que utilizam, sendo o mesmo aquele utilizado com maior frequência no geral. Desenvolvemos então, a partir dessa seleção, eixos de análises que contemplam interpretações baseadas na teorização anteriormente concebida neste trabalho, juntamente dos trechos das entrevistas. Podemos observar, primeiramente, que os jovens possuem condições de acesso à Internet tanto Wi-fi quanto acesso a dados móveis. A grande maioria - 91 dos 103 entrevistados - possui dispositivos comunicacionais móveis, como celulares ou smartphones.

Para Recuero (2014, p. 34), as inovações tecnológicas influenciam nas formas de conversação que se dão no ciberespaço: “a percepção de conversações que não se desenham apenas no espaço da oralidade é uma das primeiras observações a respeito da conversação no espaço da mediação do computador". Em nossa pesquisa, seguindo esta lógica que envolve as inovações tecnológicas, propomos a mediação através do WhatsApp onde podemos pensar as novas camadas que as conversações ganham por meio do uso do aplicativo. 


\subsection{Uso de Grupos de WhatsApp como Forma de Contato com Família, Amigos e Colegas}

É possível pensar as conversações em grupo no aplicativo através da ideia de conversações em rede, desenvolvida por Recuero (2014), de modo que estas ocorrem no ciberespaço e "constituem-se em conversações coletivas, públicas, permanentes [...], cujas características emergentes são aliadas às características da conversação mediada" (RECUERO, 2014, p. 121). Porém, na interação em grupos de WhatsApp, podemos fazer uma distinção no que diz respeito a relação com grupos sociais: enquanto na conversação em rede, proposta por Recuero (2014), a interação com grupos distintos ocorre de forma interseccionada no mesmo espaço, nos grupos do aplicativo, as conversações são segmentadas, ou seja, para cada grupo que os jovens têm contato, há um espaço separado de interação no aplicativo. Em nossa análise, observamos a forma com que os grupos sociais de relacionamento desses jovens são transferidos para grupos de WhatsApp.

Notamos que a forma de contato mais comum dos jovens entrevistados com os grupos sociais que se relacionam, tanto para amigos, quanto para colegas de estudo ou trabalho, foi o aplicativo WhatsApp. Já no que se refere à família, o que se sobressaiu foi a relação fora das ambiências digitais, mas ainda assim, no contexto da comunicação mediada por mídias digitais, o aplicativo também aparece como sendo o mais utilizado. Podemos observar nos trechos transcritos, a seguir, como o contato com a família ocorre através do aplicativo WhatsApp:

É, meu pai eu falo com ele pelo WhatsApp, no Facebook eu falo com ele, ele me liga. Aí com minha mãe, eu falo bastante pelo WhatsApp, mesmo em casa, eu também fico falando com ela, que ela também é viciada no WhatsApp. É, eu falo com minhas tias, no WhatsApp, minhas tias, minhas primas tudo moram em Aracaju, a maioria. Aí eu se comunico sempre assim. (Entrevistado 2, Nossa Senhora de Lourdes)

WhatsApp eu uso mais porque é mais pra falar com a família, não uso com...não tenho muita amizade assim, aí eu uso mais só pra família mesmo. (Entrevistado 1, Cedro) 
É comum que o contato com a família ocorra com maior frequência pessoalmente, visto que a maioria dos respondentes mora na casa dos pais, porém, para além disso, um dos jovens aponta outro dos possíveis fatores pelo qual comunicação com a família se dá com maior frequência de maneira presencial. Ao responder sobre as formas de contato com sua família, um entrevistado da cidade de Cedro de São João aborda a questão geracional, enfatizando que, para os idosos, a mediação digital não está tão presente nas conversações:

os daqui, muito pouco, porque a maioria são pessoas mais antigas e muitos não têm, né, as redes sociais, é difícil, eu tenho contato geralmente com familiares de longe, que não vejo pessoalmente porque não tenho possibilidade de ver e são pessoas mais atuais, que tem perfil no Facebook, tem WhatsApp (Entrevistado 2, Cedro)

A experiência de interação, neste caso, se dá a partir da forma espontânea com que os jovens se adaptam e se apropriam facilmente das ferramentas digitais. E um dos fatores determinantes disto, como já apontamos, ocorre devido ao acúmulo de capital tecnológico pelos jovens, que conforme Oliveira e Barbalho (2017) gera uma distinção social entre os indivíduos - neste contexto, uma distinção geracional.

\subsection{Usos e Apropriações nos Grupos de WhatsApp}

Dentre as finalidades dos grupos de WhatsApp, que os jovens respondentes fazem parte, encontram-se grupos de estudos, de amigos, da família, de colegas de trabalho, grupos para acompanhar avisos da igreja. Observamos abaixo a interação que ocorre nos grupos de colegas de estudo

A gente tem aqui o grupo da sala da gente pra falar sobre os trabalhos, atividades e tudo mais. (Entrevistado 1 Ilha das Flores)

A gente cria um outro grupo pra falar só do trabalho da escola, entendeu? (Entrevistado 1, Neópolis)

Eu uso mais o WhatsApp e até compartilhar também documentos com os colegas. Trabalhos acadêmicos, porque hoje no celular tem Word também, então já utiliza bastante.(Entrevistado 1, Canhoba) 
A partir das respostas obtidas, no que concerne à educação, podemos pensar no conceito de inteligência coletiva de Lévy (1999), que surge como uma das potencialidades da cibercultura. Podemos identificar na forma como os jovens entrevistados fazem utilização da potencialidade de coletivização dos saberes em suas trocas via aplicativo. Para Lemos (2009, p. 135), a pluralidade de conteúdo que circula no ciberespaço acaba criando "competências diferenciadas e aproveitando o caldo de conhecimento que é gerado dos laços comunitários, podendo potencializar a troca de competências".

Além disso, um tipo de grupo específico apareceu em duas cidades (Propriá e Telha), destinado a receber notícias da região. Como podemos ver nos trechos das respostas abaixo:

Eu tenho um grupo de "Propriá, como realmente é", que fala sobre tudo que acontece aqui (Entrevistado 2, Propriá)

Q: E sobre a cidade, como é que cê se informa do que tá acontecendo?

R: WhatsApp. Tem um grupo de notícias. (Entrevistado 1, Propriá)

Até pelo celular, cê vê nos 'grupo' assim do WhatsApp alguma notícia. (Entrevistado 3, Telha)

Configura-se, neste caso, uma apropriação da forma como se disseminam e como se consomem as notícias da cidade, que continuam a circular por meios tradicionais, como o rádio, mas agora ganham mais uma forma de serem veiculadas. O que chamou a atenção foi a presença do administrador do grupo das notícias de Telha entre os jovens entrevistados. Ele criou o grupo Antena Mix, em que pesquisa notícias da região e as divulga em formato de áudio no grupo, fazendo o que se assemelha a um podcast ${ }^{8}$, além de fazer divulgações publicitárias do comércio local, nesta mesma ambiência. Apresentamos abaixo um trecho da sua resposta:

R: Pizzaria, mercadinho. A Prefeitura me pede de vez em quando.

Q: Já fez isso tudo? A Prefeitura também?

R: Também tira foto ali dos, dos eventos que tem.

Q: Ah, legal.

R: Boto no grupo, divulgo. (Entrevistado 5, Telha)

Observa-se desta forma, um tipo de apropriação realizada pelo grupo entrevistado, em que o uso se dá de forma diferente da finalidade para qual o 
aplicativo foi criado. Para Recuero (2014, p. 35), "a apropriação técnica compreende o aprendizado do uso da ferramenta. A comunicação simbólica compreende a construção de sentido do uso dessa ferramenta, quase sempre de forma desviante". Sendo assim, podemos entender que no grupo de notícias Antena Mix ocorre uma espécie de microcentralização para disseminação do conteúdo, que não chega a ser uma difusão em massa devido aos próprios limites do aplicativo, uma vez que só é possível formar grupos de no máximo 256 pessoas.

\section{Considerações Finais}

Ao final desta análise, faz-se importante ressaltar que todos os municípios participantes da pesquisa estão localizados a pelo menos $98 \mathrm{~km}$ da capital do estado (distância entre Propriá e Aracaju) e, consequentemente, dos seus intensos fluxos de comunicação. No entanto, paralelamente a isso, é notável que mesmo com a distância geográfica, o contexto sociocultural no qual os jovens entrevistados estão inseridos é marcado pelas características da cibercultura (LÉVY, 2001). Dessa maneira, o aplicativo WhatsApp exerce grande influência na forma como esses jovens se comunicam.

Um dos principais fatores de destaque é a apropriação dessa mídia social como estratégia de se manter informado sobre a sua região e de compartilhar conteúdos noticiosos com as pessoas do seu convívio. Esse aspecto reforça o nosso pressuposto de que as mídias sociais proporcionam mudanças nas formas de sociabilidade e estimulam diferentes maneiras de inserção social (JACKS et al, 2017). Além disso, essa apropriação remete também ao grande potencial de interação e discussão que o WhatsApp proporciona, discutido por Souza, Araújo e Paula (2015).

No que diz respeito à natureza do uso do WhatsApp, cabe aqui retomar o que Lemos (2002) afirma sobre a possibilidade da Internet de aproximar realidades independentemente de limitações geográficas. No contexto da pesquisa, isso é reforçado à medida que se observa a troca de mensagens com parentes que moram em outras cidades ou com amigos que se mudaram para outros locais como uma das possíveis utilizações do aplicativo. 
Em contrapartida, é interessante perceber também que, mesmo com a utilização massiva dessa mídia social, o contato com a família se dá prioritariamente de maneira pessoal. Desse modo, essa particularidade pode demonstrar como há um hibridismo entre as características rurais e urbanas na forma como esses jovens se comunicam, cabendo aqui relembrar a importância de se fazer essa análise levando em conta as singularidades de cada local pesquisado.

Outro aspecto a ser observado é que, dentre os jovens que participaram das entrevistas utilizadas nesta pesquisa, um alto percentual faz parte de famílias de baixa renda. Vale acrescentar a isso o fato de que, na microrregião analisada, os municípios não são extremamente desenvolvidos e contam com o IDH (Índice de Desenvolvimento Humano) de médio a baixo ${ }^{9}$. Nessa perspectiva, considerando que $\mathrm{o}$ acesso à Internet é uma realidade nesses locais (tanto via $\mathrm{Wi}$-Fi, quanto via dados móveis), o uso massivo de um aplicativo gratuito como o WhatsApp se justifica e se configura como a possibilidade mais viável financeiramente de se manter informado e de manter contato com familiares, amigos e colegas.

Por fim, com o intuito de ampliar esta reflexão, pretendemos realizar essa mesma análise com os dados provenientes da aplicação das entrevistas na cidade de Aracaju, capital do estado de Sergipe, durante o ano de 2019. Com os resultados dessa nova pesquisa, que já está em andamento, buscaremos traçar um comparativo entre as realidades dos jovens que vivem na Microrregião de Propriá (no interior do estado) e na capital, visando encontrar aproximações e divergências no uso dessa mídia social.

\section{Referências}

BARBero, J. M. Diversidade em convergência. Matrizes, São Paulo, v. 8, n. 2, p. 15-33, 2014.

BARDIN, L. Análise de conteúdo: edição revista e ampliada. São Paulo: Edições 70, 2016.

COSTA, A. P.; AMADO, J. Análise de Conteúdo Suportada por Software. Aveiro: Ludomedia, 2018.

DOMICÍLIOS, T. I. C. Uso da internet pelo celular cresce entre os brasileiros. 2016. 
GRANERO, A. E.; COUTO, T. C. Consumo no ciberespaço: a explosão de aplicativos de dispositivos móveis que ajudam a controlar a vida na palma da mão. Revista GEMInIS, v. 4, n. 2, p. 89-105, 2013.

IBGE. Pesquisa Nacional por Amostra de Domicílios Contínua: Acesso à Internet e à televisão e posse de telefone móvel celular para uso pessoal. 2017. Disponível em: $<$ https://biblioteca.ibge.gov.br/visualizacao/livros/liv101631_informativo.pdf $>$ Acesso em: 05 abr. 2019. https://doi.org/10.21710/rch.v25i0.451

JACKS, N.; TOALDO, M. M.; MARQUES, J. Jovens Rurbanos e Mediações Tecnológicas: práticas e convivências sociais contemporâneas. Cuadernos del Claeh, v. 36, n. 106, p. 101-123, 2017. https://doi.org/10.29192/claeh.36.2.6

JENKINS, H. Confronting the challenges of participatory culture: Media education for the 21st century. Mit Press, 2009. https://doi.org/10.7551/mitpress/8435.001.0001

JENKINS, Henry; GREEN, Joshua. Cultura da conexão: Criando Valor e Significado Por Meio da Mídia Propagável. São Paulo: Aleph, 2014. https://doi.org/10.22478/ufpb.1807-8931.2017v13n2.33014

LEMOS, A. Cibercultura, tecnologia e vida social na cultura contemporânea. Sulina, 2002.

. Cibercultura e mobilidade: a era da conexão. Razón y palabra, v. 41, 2004.

. Ciber-cultura-remix. In: Seminário "Sentidos e Processos" 2005. Disponível em: https://www.facom.ufba.br/ciberpesquisa/andrelemos/remix.pdf. Acesso em abril de 2019.

. Cultura da mobilidade. Revista FAMECOS: mídia, cultura e tecnologia, n. 40, p. 28-35, 2009. https://doi.org/10.15448/1980-3729.2009.40.6314

LÉVY, P. Cibercultura. São Paulo: Editora 34, 1999. As tecnologias da inteligência, 2001.

OLIVEIRA, A. N. de; BARBALHO, A. Entre o WhatsApp e a praça da "família": relato de uma experiência teórico-metodológica. Comunicação \& Educação, v. 22, n. 2, p. 85-94, 2017. https://doi.org/10.11606/issn.2316-9125.v22i2p85-94

RECUERO, R. A conversação em rede: comunicação mediada pelo computador e redes sociais na internet. $2^{\mathrm{a}}$ ed Porto Alegre: Sulina, 2014. https://doi.org/10.15448/1980-3729.2009.38.5309

RESTREPO, E. Etnografía: alcances, técnicas y éticas. Envión editores, 2016.

RHEINGOLD, Howard. Smart mobs: The Next Social Revolution. Londres: Basic books, 2007.

SANTAELLA, L. Navegar no ciberespaço: o perfil cognitivo do leitor imersivo. Paulus, 2004. 
SILVA, Júlio César Lázaro da. História Econômica da Região Nordeste; Brasil Escola. Disponível em <https://brasilescola.uol.com.br/brasil/historia-economicaregiao-nordeste.htm>. Acesso em 17 de abril de 2019. https://doi.org/10.11606/d.85.2008.tde-29092009-154302

SIMILAR WEB Marketing Intelligence Blog.Publicação com resultados da pesquisa da empresa Similar Web sobre uso de aplicativos de troca de mensagens no mundo. Disponível em:

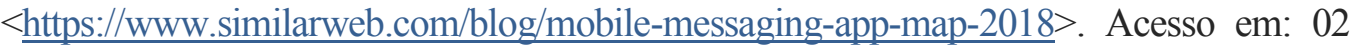
abr. 2019.

SOUZA, J.; ARAÚJO, D.; PAULA, D. Mídia social WhatsApp: uma análise sobre as interações sociais. Revista Alterjor (ECA/USP). São Paulo, ano 06, v. 1, ed. 11, p. 131165, 2015. Disponível em: http://www.revistas.usp.br/alterjor/article/view/aj11-a05. Acesso em: 05 abr. 2019.

THOMPSON, John. A mídia e a modernidade: uma teoria social da mídia. Rio de Janeiro: Vozes, 2012.

WhatsApp Blog. Blog oficial do WhatsApp para divulgação de informações de interesse da empresa. Disponível em: https://blog.WhatsApp.com/616/One-billion. Acesso em: 02 abr. 2019.

WhatsApp chega a 120 milhões de usuários no Brasil. Link - O Estado de S. Paulo, 2017. Disponível em: https://link.estadao.com.br/noticias/empresas, WhatsApp-chega-a-120-milhoes-deusuarios-no-brasil,70001817647. Acesso em: 05 abr. 2019.

Data Recebimento: $14 / 08 / 19$

Data Aprovação: 23/09/19

1 Trabalho apresentado na IJ 08 - Estudos Interdisciplinares em Comunicação do XXI Congresso de Ciências da Comunicação na Região Nordeste, realizado de 30 de maio a 1 de junho de 2019.

2 Serviço de mensagens curtas (do inglês Short Message Service).

${ }^{3}$ Serviço de mensagens multimídia (do inglês Multimedia Messaging Service) é uma tecnologia que permite aos dispositivos móveis enviar e receber mensagens multimídia. Trata-se de uma evolução dos SMS, possível graças à evolução da rede celular tradicional.

${ }^{4} \mathrm{https}: / /$ www. WhatsApp.com

5 Amparo de São Francisco, Brejo Grande, Canhoba, Cedro de São João, Ilha das Flores, Neópolis, Nossa Senhora de Lourdes, Propriá, Santana do São Francisco e Telha.

${ }^{6}$ Disponível em: https://www. WhatsApp.com/about/. Acesso em: 02 abr. 2019.

7 Financiado pela Coordenação de Aperfeiçoamento de Pessoal de Nível Superior (CAPES), a partir da aprovação no edital n ${ }^{\circ} 071 / 2013$.

8 Podcast é um arquivo de áudio em formato digital que pode ser transmitido através da internet, normalmente com o propósito de transmitir informações.

9 De acordo com a plataforma IBGE Cidades. Disponível em: https://cidades.ibge.gov.br/. Acesso em 15 abr. 2019. 